\title{
Introducing Parallelism to First-Year CS Majors
}

\author{
Barbara M. Anthony \\ Southwestern University \\ Georgetown, TX 78626 \\ anthonyb@southwestern.edu
}

\author{
D. Cenk Erdil \\ Sacred Heart University \\ Fairfield, CT 06825 \\ erdild@sacredheart.edu
}

\author{
Olga Glebova \\ Georgia State University \\ Atlanta, GA 30302 \\ glebova@cs.gsu.edu
}

\author{
Robert Montante \\ Bloomsburg University \\ Bloomsburg, PA 17815 \\ bobmon@bloomu.edu
}

\begin{abstract}
We propose to strengthen the computer science (CS) curriculum by embedding parallel concepts in a required first-semester seminar taken by all incoming declared CS majors. We introduce students to parallel computing concepts through a series of unplugged activities so that students see parallel approaches as a natural form of solution to a task. We describe a pilot offering of the class and activities, with measurements and analysis of what students self-report and their performance on assessments.
\end{abstract}

\section{CCS CONCEPTS}

Social and professional topics $\sim$ Computational thinking • Social and professional topics Computer science education

\section{KEYWORDS}

Unplugged activities, parallel and distributed computing, computing education.

\section{INTRODUCTION}

Almost all computing devices today run on multiprocessors. $\mathrm{ACM}$ and ABET guidelines recommend exposure to parallel computing concepts, yet CS programs still teach a largely sequential paradigm. A parallel programming elective fails to reach all students, and is usually offered at the upper level, by which point sequential thinking patterns have been established and parallel approaches seem obscure.

\section{BACKGROUND}

There has been a recent increase in published interest in early and sustained introduction of parallel and distributed computing concepts, including the work of Prasad et al. [3] which makes recommendations on when and how they should be introduced, motivating the importance and aligning it with recent curricular guidelines, while noting that there are still limitations on resources, particularly at the early stages. Unplugged activities are a popular way of introducing concepts without requiring programming that can be effective for both students and teachers [1].

Permission to make digital or hard copies of part or all of this work for personal or classroom use is granted without fee provided that copies are not made or distributed for profit or commercial advant0age and that copies bear this notice and the full citation on the first page. Copyrights for third-party components of this work must be honored. For all other uses, contact the Owner/Author.

SIGCSE '20, March 11-14, 2020, Portland, OR, USA

(C) 2020 Copyright is held by the owner/author(s)

ACM ISBN 978-1-4503-6793-6/20/03

https://doi.org/10.1145/3328778.3372581

\section{OVERVIEW}

At Bloomsburg University of Pennsylvania all declared first-year CS majors take a 1-credit weekly seminar during their first semester that acquaints them to college and the Computer Science major. For this study, students work in small groups on three unplugged activities that introduce them to parallel computing concepts. They are surveyed about their interest in areas of CS and their understanding of parallel approaches to problems, both before and after the unplugged activities. SOLO (Structure of Observed Learning Outcomes) taxonomy questions are used to evaluate understanding [2,4]. A reflection paper on the activities is also assigned. CS faculty at the other institutions analyze the anonymized student submissions for understanding of parallel approaches. The poster presents preliminary results of the study, and recommends future directions.

\section{CONTRIBUTIONS AND FUTURE WORK}

This work provides unplugged parallel activities for early introduction in CS, and measures their impacts on student learning. It sets the stage for similar work at other institutions, and longitudinal studies determining the impact early introduction of parallel concepts has in later courses.

ACKNOWLEDGMENTS This material is based upon work supported by the NSF under Grant No. NSF-1730527.

\section{REFERENCES}

[1] T. Bell and J. Vahrenhold. 2018. CS Unplugged-How Is It Used, and Does It Work? In Adventures Between Lower Bounds and Higher Altitudes. Lecture Notes in Computer Science, vol 11011. Springer.

[2] J. B. Biggs and K. F. Collis. 1982. Evaluating the Quality of Learning: the SOLO Taxonomy. New York, Academic Press.

[3] S. Prasad, A. Gupta, A. Rosenberg, A. Sussman, and C. Weems. 2018. Topics in Parallel and Distributed Computing Enhancing the Undergraduate Curriculum: Performance, Concurrency, and Programming on Modern Platforms. Springer Publishing Company.

[4] J. Sheard, A. Carbone, R. Lister, B. Simon, E. Thompson, and J. Whalley. 2008. Going SOLO to assess novice programmers. SIGCSE Bull. 40, 3, ACM, June 2008, pp.209-213. 